\title{
ENTRE CONTROVERSIAS CIENTÍFICO-MÉDICAS Y MOVILIZACIONES POPULARES. POBLACIÓN EPIDÉMICA Y VACUNAS CONTRA LA FIEBRE HEMORRÁGICA ARGENTINA 1958-1990
}

\author{
Graciela Agnese \\ Instituto de Historia. Facultad de Derecho y Ciencias Sociales del Rosario. PUCA \\ gracielaagnese@gmail.com
}

Recibido: 8 julio 2011; Aceptado: 26 julio 2012.

Cómo citar este artículo/ Citation: Agnese, Graciela (2013), "Entre controversias científico-médicas y movilizaciones populares. Población epidémica y vacunas contra la fiebre hemorrágica argentina 1958-1990", Asclepio 65 (1): p011. doi: http://dx.doi.org/10.3989/asclepio.2013.11

RESUMEN: La irrupción y la progresiva extensión de una nueva enfermedad epidémica, como ha sido la Fiebre Hemorrágica Argentina, a partir de la década del '50, impulsó la investigación científica médica con el objetivo fundamental de encontrar una vacuna. En el período 1959-1990 se desarrollaron tres proyectos de vacunas con distintos resultados. El objetivo de este artículo es considerar las conductas asumidas por la población epidémica en torno a las tres vacunas atendiendo a las tensiones existentes entre la población y los médicos e investigadores a cargo de las campañas de vacunación; las pugnas entre los distintos grupos científicos; el rol de la prensa y del estado.

PALABRAS CLAVE: Fiebre Hemorrágica Argentina; Investigadores; Médicos; Población; Vacunas.

BETWEEN MEDICAL SCIENTIFIC CONTROVERSIES AND MASS MOBILIZATIONS. EPIDEMIC POPULATION AND ARGENTINIAN HEMORRHAGIC FEVER VACCINES 1958-1990

ABSTRACT: The emergence and gradual extension of a new epidemic disease, as it has been the Haemorrhagic Fever Argentina, from the Decade of the ' 50 s, prompted the medical scientific research with the aim of finding a vaccine.

In the period 1959-1990 developed three projects of vaccines with different results. This article aims to consider the behavior assumed by the epidemic population around the three vaccines in response to the tensions that exist between population and physicians and researchers in charge of vaccination campaigns; the struggles between the various scientific groups; the role of the press and the State.

KEY WORDS: Argentina Hemorrhagic Fever; Researchers; Doctors; Population; Vaccines.

Copyright: (C) 2013 CSIC. Este es un artículo de acceso abierto distribuido bajo los términos de la licencia Creative Commons Attribution-Non Commercial (by-nc) Spain 3.0. 


\section{INTRODUCCIÓN}

La monotonía era el signo distintivo de la vida de los pequeños pueblos y ciudades del Noroeste bonaerense (Argentina), caracterizado por grandes extensiones de campo donde se podían observar las típicas viviendas rurales construidas con adobe, pisos y patios de ladrillo o de tierra, tejados de madera o zinc, en las que se utilizaba como material aislante el barro con paja, siendo muy poco frecuentes las construcciones de concreto. El panorama se completaba con pequeños pueblos que no contaban con calles pavimentadas, servicio de agua corriente ni alcantarillado y las distancias entre las ciudades mayores, con instalaciones sanitarias más adecuadas, eran bastantes considerables (Metler, 1970, p.8). La zona forma parte de la Pampa Húmeda de Argentina, sector agrícola por excelencia y en torno al cual giraba, como en la actualidad, la economía del país, sustentada en el modelo agroexportador.

Los médicos de estos sitios atendían a los pacientes en la pequeña sala de primeros auxilios del pueblo o en sus domicilios, dado que sólo las localidades más pobladas contaban con hospitales o sanatorios privados.

Esta apacible región se vio perturbada, en los inicios de la década del '50, con la irrupción de "la peste", como la llamaron los lugareños. Se presentaba como una aparente gripe pero derivaba en graves hemorragias o trastornos neurológicos. Posteriormente fue identificada como una nueva enfermedad y denominada Fiebre Hemorrágica Argentina (FHA ${ }^{1}$.

Los brotes comenzaron a reiterarse. En 1958 los primeros casos se registraron en O'Higginis, pequeña localidad cercana a Junín Desde este lugar la virosis se extendió abarcando una superficie de $16.274 \mathrm{Km}^{2}$, con una población de 268.049 habitantes (Pirosky et al., 1959, p. 13) y, un índice de mortalidad que osciló entre un 19,43\% a un 50\% (Martínez Pintos, 1960, p.29; Pirosky et al., 1959, p. 15; Ruggiero et al., 1982, p. 2). Además, la enfermedad se presentaba en tiempos de cosecha, desde fines de verano hasta la culminación del invierno, siendo los principales afectados trabajadores rurales transitorios, particularmente recolectores de maíz a mano, varones de 20 a 40 años, en su mayoría conocidos como "peones golondrina". En la zona sólo un $30 \%$ de la cosecha de maíz se levantaba a máquina, el resto a mano, de manera que estos peones, que se trasladaban desde las provincias del Norte del país para realizar la cosecha, resultaban imprescindibles (Pirosky et al., 1959, p. 25).

La intensidad del brote del '58 suscitó una honda preocupación en la población epidémica cercana al pánico. Desde el 5 de junio, el periódico La Razón, comenzó a publicar artículos en los que describía el temor de los vecinos del área afectada, los padecimientos de los enfermos y las dolorosas vivencias de los familiares de las víctimas. Esto, sumado a artículos de otros periódicos nacionales como La Nación o La Prensa, si bien de menor envergadura, fueron un factor de presión para las autoridades, unido a la importancia económica de la región.

Arturo Frondizi había asumido la presidencia de la Nación en mayo de 1958, y Oscar Allende la gobernación de la provincia de Buenos Aires; ambos dirigentes de la Unión Cívica Radical Intransigente. La intervención del estado nacional como provincial se hizo notoria a partir de la segunda quincena de junio. Además del envío de medicamentos, ropa de cama, ambulancias y brigadas sanitarias, ambas administraciones resolvieron crear comisiones científicas. El Ministerio de Salud de la Nación designó a la Comisión Nacional Ad Hoc presidida por el Dr. Ignacio Pirosky, Director del Instituto Nacional de Microbiología (Malbrán), e integrada por investigadores del mencionado Instituto ${ }^{2}$. El Ministerio de Salud Provincial creó la Comisión de Estudio de la Epidemia del Noroeste Bonaerense. También el virólogo Armando Parodi - de la Cátedra de Microbiología y Parasitología de la Universidad de Buenos Aires-, con el Dr. Humberto Rugiero - de la Cátedra de Enfermedad Infecciosas - había organizado la Comisión de la Facultad de Medicina de la Universidad de Buenos Aires (UBA) ${ }^{3}$ luego de que Parodi recibiera una convocatoria por parte de médicos de Junín.

Mientras la Comisión de la provincia de Buenos Aires se dedicó a la prevención y atención de los enfermos, los equipos liderados por Parodi y Pirosky se ocuparon de la investigación científica. Estas dos comisiones, sin coordinación y con una gran competencia ${ }^{4}$, en pocos meses de trabajo, durante 1958, lograron aislar el virus Junín - agente etiológico de la enfermedad-, y pudieron observar el curso de la virosis a través de una inoculación experimental del agente viral por ellos aislado. Además el grupo Parodi realizó estudios sobre la evolución clínica, la patogenia de la enfermedad y comenzaron a desarrollar modelos experimentales animales. El equipo Pirosky demostró la especificidad del virus, descartaron otras posibles etiologías, establecieron los caracteres anatomoclínicos de la virosis, realizaron observaciones epidemiológicas del brote epidémico e investigaciones virológicas (Agnese, 2003). El aislamiento del virus causal de la enfermedad posibilitaba la obtención de una vacuna, única herramienta eficaz para poder controlarla.

La Fiebre Hemorrágica, como "una mancha de aceite", metáfora utilizada para describir lo imprevisible que resultaba poder determinar hacia dónde se extendería, fue ampliando, progresivamente, la región afectada. En 1963 irrumpió en el sudeste de Córdoba, en la zona de Laboulaye; en el '64 en el Partido de Pergamino (provincia de Buenos Aires); desde 1968 
en el sur de Santa Fe y, en 1977 el Noreste de la provincia de la Pampa. Así, el área endemo-epidémica ocupó una superficie de alrededor de $100.000 \mathrm{~km}^{2}$, con más de un millón de habitantes, abarcando la región agrícola-ganadera más rica de la pampa húmeda (Maiztegui, 1977, p. 361) (ver Figura 1).

El impacto socioeconómico de la enfermedad, impulsor del interés del Estado ${ }^{5}$ y, la posibilidad de asegurarse la primacía en el campo científico, propulsaron el desarrollo de tres proyectos de vacuna en el período 1958-1990. El objetivo de esta ponencia es presentar algunos avances de investigación sobre las conductas asumidas por la población epidémica en torno a estos proyectos, atendiendo a las tensiones existentes entre la población y los médicos e investigadores a cargo de las campañas de vacunación; las pugnas entre los distintos grupos científicos; el rol de la prensa y del estado.

La enfermedad como objeto de reflexión histórica ha ganado un destacado espacio en la historiografía latinoamericana en las últimas décadas. En años recientes, en Argentina, se han desarrollado valiosos estudios históricos sobre la sanidad rural que han producido conocimientos y manifiestan el interés que han suscitado temáticas afines a este artículo, siendo la Fiebre Hemorrágica Argentina una enfermedad rural de la segunda mitad del siglo XX (Di Liscia, 2011; Álvarez, 2010; Kreimer et al., 2010a; Zabala, 2010; Carter, 2008).

\section{TEMOR Y CONFORMIDAD: LA VACUNA DE PIROSKY}

La preparación de una vacuna contra el Mal de los Rastrojos ${ }^{6}$, como se conocía popularmente a la enfermedad, figuraba como prioridad en el Programa de Trabajo de la Comisión Nacional para el año 1959 (Pirosky et al., 1959, p. 143) ${ }^{7}$. El 20 de julio el Ministro de Salud, Dr. Héctor Noblía, anunció a los periodistas, como un gran triunfo de la ciencia argentina, la obtención de una vacuna preventiva ${ }^{8}$. Informó que ya se había realizado una experiencia de campo con más de quinientas personas vacunadas en la zona de la enfermedad y, que la vacunación se iniciaría en breve lapso. Según sus expresiones, las pruebas de laboratorio y experiencias realizadas en voluntarios humanos eran concluyentes ${ }^{9}$.

Los periódicos nacionales más importantes, Clarín, La Nación, La Prensa, El Mundo, se hicieron eco de la altisonante declaración del Dr. Noblía ${ }^{10}$. Sin embargo, desde los primeros días de agosto, el diario La Razón, comenzó a publicar detalles sobre la enfermedad del

Figura 1. Extensión progresiva del área endémica de Fiebre Hemorrágica Argentina.

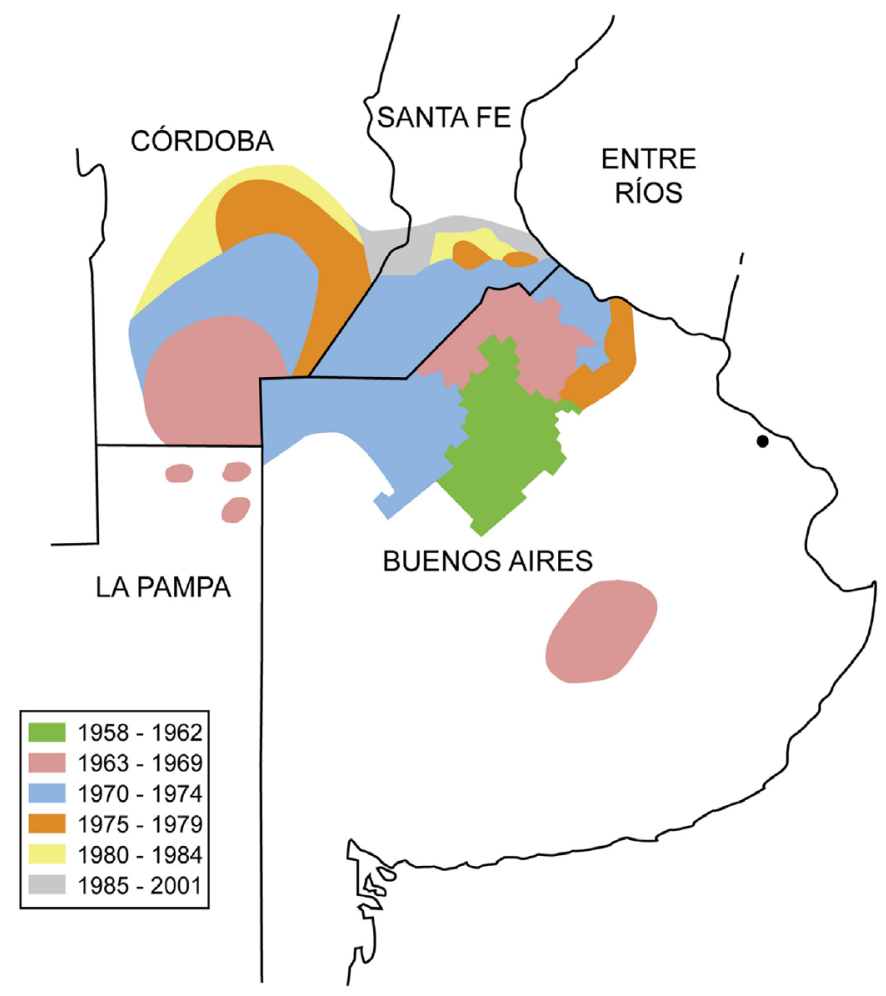

Fuente: Archivo del Instituto Nacional de Enfermedades Virales Humanas “Dr. Julio I Maiztegui”, Pergamino (Argentina). 
Dr. Pedro Martini y el fallecimiento de la técnica Yolanda Righetti, quiénes habían trabajado juntos, en el Instituto Malbrán, en el desarrollo de la vacuna ${ }^{11}$; también comentaban sobre la enfermedad y posterior recuperación de otros investigadores que trabajaban con la virosis hemorrágica en el citado instituto. Además, el mismo periódico denunció que la vacuna había sido experimentada en veinte alienadas del Hospital Neuropsiquiátrico de mujeres de Buenos Aires (Agnese, 2005, pp.153-166), ensayo que Noblía negó enfáticamente durante una interpelación que se realizó en la Cámara de Diputados ${ }^{12}$. Como corolario de estas denuncias y rumores, el 18 de agosto los periódicos anunciaron el fallecimiento del Martini calificado como mártir de la ciencia ${ }^{13}$.

Luego del anuncio sobre la vacuna, tanto los miembros de la Comisión Provincial como los médicos de la zona epidémica, manifestaron ignorar el valor de la vacuna y si ésta se estaba aplicando en el área afectada, pues sólo conocían la información publicada en los medios periodísticos, testimoniando la falta de coordinación y de intercambio de información entre los equipos que trabajaban sobre la cuestión.

El primer grupo de vacunación estuvo conformado por Pirosky y el Dr. Ernesto Molinelli y se desarrolló durante el período julio-octubre de 1959. El 8 de abril de 1960 el ministro Noblía, acompañado por el director de la Organización Mundial de la Salud zona VI, Dr. Emilio Budnick y de profesionales de la zona, inauguró el Primer Centro Nacional de Vacunación contra la Fiebre Hemorrágica en el Hospital Regional de Junín (NO provincia de Buenos Aires, en la zona epidémica). Fue en este año cuando algunos periódicos de la zona epidémica anunciaron la elaboración de una vacuna preventiva o hicieron referencia a personas ya vacunadas ${ }^{14}$. Durante 1961 el operativo de vacunación voluntaria continuó.

La taxativa concepción de la distancia existente entre el trabajo médico y del científico de los integrantes del equipo liderado por Pirosky habría determinado una relación respetuosa con los médicos del área epidémica pero muy distinta a la que sostenía Parodi y su grupo, quiénes trabajaron en colaboración con estos profesionales. Posteriormente se suscitó un gran distanciamiento con los hombres del Malbrán por las críticas que éstos realizaron al uso de plasma de convaleciente como tratamiento específico ${ }^{15}$, por la total identificación de los médicos locales con el equipo de Parodi y, por la notoria competencia existente entre las dos comisiones científicas. Así, las campañas de vacunación, que se implementaron en el trienio 1959-1961, estuvieron a cargo exclusivamente de personal del Malbrán.

Los pobladores de los partidos afectados del Noroeste bonaerense desarrollaron un gran temor a contraer la enfermedad, asociada con una muerte casi segura. El miedo a la virosis significó la adopción de medidas de prevención y, fundamentalmente la consulta precoz con los médicos de la zona epidémica, los primeros en intervenir ante esta problemática. Estos profesionales, particularmente los nucleados en el Centro de Investigación y Tratamiento ${ }^{16}$ que surgió en el Hospital de Junín, fueron reconocidos por la población epidémica como únicos especialistas en diagnóstico y atención de Fiebre Hemorrágica.

Desde fines del siglo XIX la vacunación, por su eficacia como medida profiláctica, se había extendido si bien en un principio había encontrado resistencia tanto en círculos médicos como en la población misma (Babini, 2000, p.110). En Argentina las primeras campañas de vacunación tuvieron lugar cuando médicos higienistas impulsaron la vacunación antivariólica. Luego de varios intentos, la ley de vacunación obligatoria para la ciudad de Buenos Aires fue aprobada en 1886 y, para el resto del país en 1904. La resistencia a la medida se encontraba en los sectores populares de la población "partícipes de una cosmovisión fatalista y también temerosos de aceptar un remedio que a la vez, producía la enfermedad" (Di Liscia, 2011, p. 414). $Y$, en profesionales médicos que consideraban que esta práctica era "poco eficaz, engorrosa y costosa" (Di Liscia, 2011, p. 414). Al comenzar el siglo XX el estado nacional, a través del Departamento Nacional de Higiene, impulsó la vacunación contra la viruela en el interior argentino: "la resistencia - por parte de la población- no cesó pero en general la práctica se hizo cotidiana y habitual" (Di Liscia, 2011, p. 491).

Sin embargo hay testimonios sobre conductas de rechazo a la vacunación contra la FHA por parte de habitantes del Noroeste Bonaerense. Rosa Finamore, enfermera idónea en O'Higgins, donde trabajaba con el médico del pueblo, el Dr. Locícero, recordó que "el doctor me mandó junto con Juan Desa, que trabajaba en "la Sala" - Sala de Primeros Auxilios del pueblo-, no queríamos ir porque teníamos un susto tremendo, pero nos dijo que teníamos que ir, fuimos y nos vacunamos". Eber Pagano, otro vecino de O'Higgins, recuerda que se hizo una campaña de vacunación pero que la gente no fue "porque había dudas, no se la vio como algo eficaz [...] no daba la seguridad que el paciente necesita en esos casos, [...] de nuestro grupo familiar nadie fue" 17 .

Conducta diferente a la sostenida por los peones golondrina -foráneos de la zona epidémica- quienes, asustados ante la posibilidad de contraer la enfermedad, sólo aceptaron trasladarse a recoger la cosecha de 1960, en el Noroeste bonaerense, ante el compromiso asumido por el ministro Noblía de aplicarles la vacuna ${ }^{18}$. No obstante, entre adhesiones y rechazos, la vacuna se habría aplicado a más de 15.000 perso- 
nas (Metler, 1970, pp. 31-32) que representaban el $6 \%$ del total de la población del área epidémica.

El 29 de marzo de 1962 el presidente Frondizi fue depuesto por las Fuerzas Armadas. José María Guido, presidente provisional del Senado, en cumplimiento de la ley de acefalía, asumió la presidencia, logrando salvar las formas constitucionales, si bien este formalismo no escondía el gobierno directo de los militares. Una de las primeras medidas del Dr. Tiburcio Padilla, designado ministro de Salud Pública y Asistencia Social de la Nación, fue la intervención del Instituto Malbrán y la suspensión de su director. Esta medida significó el desmembramiento de la Comisión Nacional y la suspensión de todos los trabajos vinculados con la vacuna (Agnese, 2007).

En la zona afectada por la Fiebre Hemorrágica volvieron a surgir signos de preocupación y voces de alarma, con expresiones críticas hacia la gestión del gobierno nacional. Durante el mes de julio entidades como cooperativas agrícolas, la Sociedad Rural ${ }^{19}$ y particulares, con apellidos ilustres, vinculados a esta actividad (Morea, Ocampo, Pueyrredón, Blaquier), impulsados fundamentalmente por la escasez de braseros, quiénes temerosos por contraer la virosis rehusaban trasladarse a la zona epidémica, con la consecuente elevación del jornal, reclamaron al presidente por la falta de resultados de las medidas adoptadas en la lucha contra la enfermedad señalando que las víctimas que esta producía se debían a la desaprensión de las autoridade ${ }^{20}$. También la filial Rojas - localidad del área epidémicade la Federación Agraria Argentina ${ }^{21}$ dirigió una nota el presidente Guido en la que expresaban "la afligente situación por la que atraviesa la familia campesina, amenazada [...] por el [...] "Mal de los Rastrojos" y, dado que en la zona se había iniciado la vacunación, solicitaban que el estudio continuara22. Pocos días después, el diario La Prensa, comentaba la inquietud de la población del área epidémica debido el incremento en el número de casos, señalando que las versiones contradictorias sobre la vacuna "habían contribuido a sembrar el des-

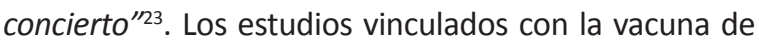
Pirosky no volvieron a ser retomados.

\section{RECLAMOS Y MOVILIZACIONES POR LA XJ CLON 3}

En 1963 la región epidémica se extendió abarcando la zona de Laboulaye, al sur de la provincia de Córdoba. En 1964 el Mal de los Rastrojos hizo su aparición, en forma muy intensa, en el partido de Pergamino (provincia de Buenos Aires), determinando que el Instituto Malbrán centralizara sus estudios en la zona. Al año siguiente, en marzo, un equipo de médicos e investigadores ${ }^{24}$, con la coordinación del Dr. Julio Maiztegui, se instaló en la mencionada ciudad. Así, surgió el Centro de Estudios de FHA que, como ya había ocurrido con el de Pirosky, disputaría al equipo de Parodi, el liderazgo o preemi- nencia en orden a los logros en el campo científico vinculado con la Fiebre Hemorrágica.

En la cátedra de Microbiología y Parasitología de la Facultad de Medicina de la Universidad de Buenos Aires el grupo dirigido por Armando Parodi continuaba con sus trabajos de investigación. Y, si bien debían lidiar con la falta de recursos, la alteración del orden institucional no había afectado las tareas científicas como en el caso del grupo del Malbrán.

En 1968 comenzaron los ensayos en seres humanos con una vacuna desarrollada por el equipo que se aplicó en siete profesionales de la Cátedra. Al observarse que era inocua resolvieron ampliar el estudio vacunando, con la denominada XJ Clon 3, a un grupo de 64 personas de la zona epidémica (Barcelona et al., 1969; Weissenbacher et al., 1969).

El 23 de junio de 1969, en pleno proceso de desarrollo y evaluación de la vacuna, inesperadamente, murió el Dr. Parodi, dejando al equipo de la Facultad de Medicina de la UBA sin su guía y mentor. El 25 de noviembre se inició un programa de vacunación voluntario que contaba con el auspicio de los Ministerios de Salud de la Provincia de Buenos Aires y de la Nación y, que comprendía a los partidos de Junín y Rojas (NO bonaerense, área epidémica). En un acto oficial, realizado en el Hospital Regional de Junín, se vacunó al director de Epidemiología del Ministerio de Salud de la Provincia al Secretario de la Zona Sanitaria III y al presidente de la Sociedad Rural de Junín ${ }^{25}$, para dar inicio al programa.

Hemos relatado que los médicos de la zona epidémica, más específicamente los profesionales que se desempañaban el Centro de Investigación y Tratamiento de Fiebre Hemorrágica Argentina de Junín, eran reconocidos por la población epidémica como los únicos especialistas en diagnóstico y atención. Profesionales que, además, desde 1958 trabajaban estrechamente con el grupo de Parodi. Fueron estos médicos los encargados de conseguir los voluntarios y efectuar los controles.

En 1969 el diario de Junín la Verdad convocaba a 1000 voluntarios expresando "el equipo de Junín considera que cuenta con un arma preventiva [...] es la vacuna [...] hoy en la hora de la victoria que ya parece próxima [...] Junín ha sido elegida para la aplicación de un plan piloto para 1000 pacientes voluntarios. [...] Este llamado a la solidaridad social está avalado por horas de estudio, por el prestigio de sus cinco integrantes - refiriéndose a los médicos que integraban el Centro de Prevención y Tratamiento de Junín ${ }^{26}-$ [...] mencionando como ejemplo a uno solo de ellos nos encontramos con el nombre del Dr. Héctor A Milani, ilustre por sus descubrimientos ${ }^{\prime 27}$. Claro testimonio de la sustentación de la campaña de voluntarios en la figura de los médicos del centro de Junín. 
La población acudió sin reparos, "alentados por el conocimiento de que primero se habían vacunado profesionales médicos ${ }^{28 "}$; "fuimos todos a Junín a vacunarnos, en chata, en colectivos, en auto... Cada uno iba como podía [...] Juan Valentín, cuándo él fue a Junín, quedaban solamente cuatro vacunas, pero iba con su mujer y sus tres hijos. El no se la aplicó para que pudiera hacerlo su familia"29.

Durante los primeros meses de 1970 los médicos de Junín afirmaron que antes de concluir ese año, se iniciaría la vacunación masiva con la XJ Clon $3^{30}$. El brote del '70 fue prácticamente tan intenso como el del año anterior con un total de 1508 enfermos $^{31}$. Durante el mes de mayo, cuando los brotes adquirían la mayor intensidad, una Comisión Popular de Rojas, volvió a realizar reclamos tales como la designación de profesionales en el Hospital provincial ante jubilaciones o fallecimientos, el nombramiento de un médico para la sala de virosis que solo contaban con un profesional para cumplir funciones durante todo el día y, la nominación de enfermeras. Así, el brote epidémico, como es usual, vehiculizaba preocupaciones y demandas. La inquietud se extendía a los voluntarios que había recibido la vacuna del equipo de la Facultad de Medicina de la UBA, al no tener información sobre los resultados de la misma ${ }^{32}$.

Durante el mes de noviembre, en las primeras Jornadas Nacionales sobre Fiebre Hemorrágica celebradas en la localidad de Laboulaye (provincia de Córdoba), mientras el equipo de Junín con el Dr. Héctor Ruggiero auspiciaban la aplicación de la vacuna en las áreas epidémicas, otros investigadores comenzaron a señalar la posibilidad que pudiera llevar elementos tóxicos u oncogénicos.

Entre mayo de 1968 y febrero de 1971 fueron vacunados grupos de 64, 159 y 413 voluntarios de la zona epidémica de la provincia de Buenos Aires ${ }^{33}$, es decir, que la vacuna se aplicó a un total de 636 personas (Frigerio, 1977), que representaban el 0,08\% del total de la población del área epidémica. Los estudios realizados en los voluntarios demostraron que la vacuna era inocua, si bien se experimentaba fiebre entre el 3 al 10 día y, estaba comprobado que inducía la formación de anticuerpos en más del $90 \%$ de los voluntarios $^{34}$, es decir, que producía inmunidad. Los resultados fueron promisorios si bien el número de 636 vacunados era limitado para formular resultados concluyentes. Según los médicos del Centro de Junín se podría haber aplicado a un mayor número de voluntarios pero faltaron dosis: "hubo más voluntarios que vacuna, en una proporción mil a uno"35. La falta de dosis habría obedecido a la escasa capacidad de producirlas por parte del grupo de Parodi, dado que desempeñaban sus tareas en un ámbito universitario, sin poder dedicarse exclusivamente al proyecto, y sin contar con un adecuado laboratorio para la producción de vacunas.

Ante las objeciones del ámbito científico, el Ministerio de Salud Pública de la Nación, a fines de 1971, suspendió la aplicación de la vacuna y requirió la opinión de investigadores en Fiebre Hemorrágica ${ }^{36}$ y de la Academia Nacional de Medicina. Ambas evaluaciones fueron coincidentes al señalar que dado que la vacuna no había sido desarrollada conforme a las pautas establecidas por la Organización Mundial de la Salud ${ }^{37}$, existiendo un riesgo hipotético, debía suspenderse su aplicación en humanos si bien consideraban necesario profundizar los estudios sobre la misma ${ }^{38}$.

Divulgada por la prensa la decisión de suspensión de la aplicación de la vacuna, se suscitó un movimiento de alarma entre los pobladores de la zona epidémica, acicateado por las declaraciones a la prensa de los médicos de Junín quiénes sostuvieron que la medida no obedecía a posibles efectos nocivos que la vacuna podía causar, afirmando con vehemencia la validez y eficacia de la misma ${ }^{39}$. Al mismo tiempo muchos de los voluntarios temían por las consecuencias que podían sufrir, al reiterarse en artículos periodísticos las declaraciones de organismos y autoridades sanitarias en las que aclaraban que aún no había estudios definitorios sobre el valor de esta vacuna.

A fines de los años '60, más precisamente en 1968, la enfermedad se extendió al sur de la provincia de Santa Fe. Así, de una zona endemoepidémica de $16.000 \mathrm{~km}^{2}$ cuadrados en 1958 , en los inicios de los '70, la virosis ocupaba una superficie de $80.000 \mathrm{Km}^{2}$ con una población de más de 800.000 habitantes (Sabatini y Maiztegui, 1970, p.116).

El 25 de mayo de 1973 un nuevo intento de régimen democrático se inició en el país con la asunción de Héctor Cámpora cuya victoria electoral significó el retorno del Peronismo al poder. En Junio, Juan Domingo Perón, regresó definitivamente a la Argentina, luego de dieciocho años de proscripción. Las esperanzas de muchos de regresar a una época "dorada" no se concretaron y el país se hundió más en la violencia, la crisis política y socio-económica.

Tanto en 1973 como en 1974 se desarrollaron intensos brotes, particularmente en el Partido de Pergamino, con un total de 1043 y 1002 enfermos $^{40}$, respectivamente, si bien el índice de mortalidad había descendido, ubicándose entre el 3 al 10\% debido, fundamentalmente, al diagnóstico precoz. El periódico El Tiempo de Pergamino en relación el rol desempeñado por el Estado denunciaba "desidia y hasta indiferencia de las autoridades estatales [...], tanto de la nación, como de la propia provincia de Buenos Aires [...] desgraciadamente debemos pensar que para que nuestras autoridades se interesen vivamente sobre tan dramática 
situación, el flagelo tiene que pisar los umbrales de la Avenida general Paz. [...] parte de esta responsabilidad, está compartida [...] por los representantes de los gobiernos que precedieron al actual, a lo largo de esta azarosa década, en que Pergamino, sus pueblos de campaña, las ciudades vecinas [...] perdieron centenares o tal vez millares de vecinos ${ }^{\prime \prime 1}$. Recordemos que, desde 1964, funcionaba un centro de atención e investigación en Fiebre Hemorrágica, dirigido por el Dr. Julio Maiztegui.

El recrudecimiento de la epidemia ponía en evidencia la necesidad de contar con una vacuna y generó la movilización de la opinión pública. Autoconvocados en el local de la Unión Ferroviaria de la ciudad, unos 250 vecinos resolvieron impulsar la creación de una Comisión de lucha contra el Mal de los Rastrojos "con el objetivo principal de lograr que las autoridades competentes se dispongan a encarar la definitiva solución del problema"42. De la convocatoria se hicieron eco diversas instituciones como la Cámara de Comercio e Industria, Federación Agraria, Clubes deportivos, el Círculo Universitario, Asociación Médica y Concejales. Denunciaban que desde hacía diez años Pergamino padecía "este flagelo" y que en ese lapso no había disminuido el riesgo de la enfermedad, el número de casos ni el número de fallecidos ${ }^{43}$. Y, se llegó a proponer un paro general en señal de protesta.

En este contexto se suscitó una ardorosa polémica en torno a la validez de la XJ Clon 3. Marino Aguirre, concejal de la Unión Cívica Radical, y enfrentado con el Dr. Maiztegui ${ }^{44}$, denunciaba que en orden a las investigaciones había "hijos y entenados" ya que sólo se apoyaba a determinados sectores - aludiendo a Maiztegui-, postergando al grupo que había logrado desarrollar la vacuna ${ }^{45}$. Los concejales del Frejuli ${ }^{46}$ en nota enviada a Perón, solicitaban ayuda, sosteniendo la necesidad de instalar un Instituto de Investigación en la zona epidémica ${ }^{47}$, proyecto que impulsaba el mencionado Dr. Maiztegui. Los médicos de Junín insistían en la necesidad de aplicar la XJ Clon 3, mientras autoridades sanitarias afirmaban que no había comprobación fehaciente de su poder inmunológico y que existían reparos que era necesario eliminar. El Prof. Alfredo Rabinovich, Coordinador de la Subárea de Protección y Promoción de la Salud del Ministerio de Salud nacional, agregaba que los equipos y las condiciones edilicias no eran las adecuadas; y que se requería de una elevada inversión, cuando el impacto de la enfermedad no era tan relevante: sobre cien mil personas expuestas enfermaba el uno por ciento ${ }^{48}$; declaración que ubicaba en su real dimensión como problema sanitario a la Fiebre Hemorrágica.

Una declaración suscripta por los médicos del Centro de Fiebre Hemorrágica de Junín, respondiendo a los comentarios negativos en torno a la vacuna, afirmaba la validez científica de la misma, la seriedad de los estudios, expresando que "todas las objeciones expuestas contra ella son de orden hipotético o imaginario", siendo la orden de suspensión "caprichosa", aclarando que se estaba en condiciones de fabricar la vacuna. Los doctores Magnoni, Cintora, Ruggiero, Héctor A. Milani y Pérez Izquierdo se comprometían "por sus propios medios, y sin erogaciones mayores" a vacunar a la cantidad de personas que hiciera falta", una vez que les proveyeran las dosis necesarias ${ }^{49}$. La altisonante declaración fue secundada por una solicitada firmada por "Vecinos de Rancagua", en donde señalaban que en la zona de influencia de esta pequeña localidad se contaba con 220 vacunados, quienes no habían padecido el mal y tampoco habían sufrido otros efectos secundarios. Los integrantes del equipo de la Facultad de Medicina de la UBA, en aquél momento, guardaron silencio. La Dra. Mercedes Weissenbacher, quien intervino en el desarrollo de la XJ Clon3 expresó, en su testimonio oral, que siendo conscientes de las objeciones que podían hacerse a la vacuna, el mismo equipo había resuelto no continuar con la vacunación con el objetivo de continuar los estudios para desarrollar una vacuna más adecuada.

En medio de la polémica, la Secretaría de Salud Pública de la Nación se preocupaba por aclarar que los estudios en torno a esta vacuna continuaban bajo la dirección del Prof. Marcelo Frigerio, quien se desempeñaba como nuevo titular de la Cátedra de Microbiología y Parasitología de la Facultad de Medicina de la UBA. Las autoridades sostenían que se había reforzado el apoyo a la cátedra.

Las diversas declaraciones, desmentidas, opiniones a favor y en contra, incrementaron la inquietud popular en Pergamino, adonde llegaban enfermos de Fiebre Hemorrágica desde el sur de Córdoba y Santa Fe. El 16 de julio de 1974 se realizó una reunión en el Concejo Deliberante de la ciudad, con la presencia de autoridades sanitarias de la Nación y de la Provincia, investigadores del Instituto Malbrán y médicos de Junín ${ }^{50}$. Las conclusiones a las que arribaron, según un Comunicado de Prensa de los concejales oficialistas (FREJULI), fueron que en la preparación de la XJ Clon 3 se había utilizado material que podría resultar potencialmente peligroso en su aplicación ${ }^{51}$.

El diario de Pergamino "La Opinión" expresó: "el común de la gente asiste, entre pasiva y atónita, a la guerra de palabras de los sectores profesionales que se embanderan en pro y en contra de la vacuna [...] Por un lado se afirma que es la única posibilidad de frenar el mal, en tanto que, por el otro - sin términos medios-, se la califica como rotundo fracaso" ${ }^{\prime \prime 2}$. A fines del invierno del '74, concluido el brote epidémico, la polémica en los medios de comunicación se fue acallando, como fue desapareciendo, también, el movimiento de alarma de la población. 
En estudios realizados en voluntarios vacunados, entre 7 a 9 años después de haber recibido la XJ Clon 3 (1977/1978), se observaron anticuerpos en un 83\%, sin que hubieran desarrollado otra enfermedad a causa de la vacuna ${ }^{53}$.

\section{SEIS MIL VOLUNTARIOS PARA LA CANDID}

Desde 1965, como hemos narrado, funcionaba en Pergamino (provincia de Buenos Aires, nueva área epidémica desde el '64) un Centro de Investigación y Tratamiento surgido a instancias del Dr. Julio Maiztegui. Producido el golpe de estado en marzo del '76, el Dr. Maiztegui fue designado como Coordinador de la IV Zona Sanitaria (partido de Pergamino) de la provincia de Buenos Aires ${ }^{54}$. El grupo científico por él liderado se había posicionado día a día y año tras año como centro de investigación, prevención y tratamiento.

En 1977 el Gobierno Nacional consideró prioritario la obtención de una vacuna a partir de recomendaciones surgidas en un Seminario Internacional sobre Fiebres Hemorrágicas (1976), organizado por el Ministerio de Salud de la Nación y la Oficina Sanitaria Panamericana. Desde 1975 la OPS impulsó la adopción de la estrategia de atención primaria de la salud ${ }^{55}$; entre los programas derivados de esta estrategia se encontraba el de la inmunización (Cueto, 2004a). En el caso de la Fiebre Hemorrágica, la vacuna debía ser financiada por el estado y de acceso gratuito para la población, ya que estaba categorizada como "droga huérfana". Es decir, un producto imprescindible para una población restringida, cuyo nivel de demanda no la hacía comercialmente interesante para los laboratorios privados ${ }^{56}$

Al año siguiente el Gobierno Nacional designó al centro de Pergamino como Instituto Nacional de Estudios sobre Virosis Hemorrágicas (INEVH) y sede de un Programa Nacional de Lucha contra la FHA que comprendía actividades de vigilancia epidemiológica, diagnóstico, tratamiento y educación para la salud. La medida evidenciaba la consolidación del proceso de institucionalización de la enfermedad como problema sanitario de primer orden si bien en términos de morbiletalidad la virosis hemorrágica no podía contarse entre los problemas sanitarios de mayor impacto en el país ${ }^{57}$. No obstante el Mal de los Rastrojos afectaba áreas de la región pampeana, en tiempos de cosecha, circunstancias que habían impulsado, como hemos señalado, el interés del estado debido a que los brotes habían activado la elevación del jornal del peón golondrina, encargado de la recolección, y, ocasionaban pérdidas a las compañías aseguradoras.

Julio Maiztegui, desde los inicios de su trabajo, realizó tareas relacionadas con educación para la salud, logrando vincular el trabajo científico tanto con la población afectada como con los médicos de estas poblaciones, los primeros que iban a intervenir ante un brote epidémico. El mismo Maiztegui y, un reducido grupo de investigadores que trabajaban con él, visitaban los pueblos afectados por la epidemia dando charlas en escuelas, en un galpón que era utilizado por los bomberos del lugar, en cooperativas agrarias, en todo sitio donde hubiera unas pocas o muchas personas congregadas, preocupadas, por el Mal de los Rastrojos. El Instituto de Pergamino era centro de referencia y de internación para toda el área epidémica, es decir, a dónde eran derivados los pacientes, sin importar cual fuera la provincia de origen, por políticas definidas desde el ámbito nacional pero también por decisión de la población afectada que reconocía en Maiztegui y su grupo como únicos especialistas en FHA, como antes había ocurrido con los médicos del centro de Junín.

Como corolario de la decisión política adoptada en orden a la obtención de una vacuna, el Gobierno Nacional suscribió el convenio ARG/78/009 con Naciones Unidas a través de su Programa para el Desarrollo, la Oficina Sanitaria Panamericana y el Instituto de Investigaciones en Enfermedades Infecciosas del Servicio de Sanidad del Ejército de Estados Unidos (USAMRII). EI convenio, en el que intervenía el Instituto de Pergamino, posibilitaba enviar un especialista al USAMRII para desarrollar una vacuna; y, el gobierno argentino, se comprometía a construir en Pergamino un laboratorio de Virología de Alta Seguridad para producir la misma una vez que estuviera desarrollada. El Dr. Julio Barrera Oro, en ese entonces, jefe del Departamento de Virus del Instituto Malbrán, fue designado para viajar Estados Unidos.

Seis años después de la firma del convenio, más precisamente en 1984, Julio Barrera Oro logró desarrollar una vacuna a la que denominó Candid ${ }^{58}$. La noticia no llegó a los periódicos. La continuidad del Programa Nacional de Lucha y Prevención había posibilitado, en el área de Educación para la Salud, la distribución entre la población de folletos, afiches, casetes y videocasetes destinados a programas radiales y televisivos, charlas informativas y reuniones de actualización para médicos y bioquímicos de las localidades en riesgo. Como resultado de estas acciones el $86 \%$ de los habitantes de toda la región afectada tenían información sobre la Fiebre Hemorrágica, el 46,3\% conocía las medidas preventivas, el $52,5 \%$ sobre los síntomas y el $63,4 \%$ sobre el tratamiento específico; un $68 \%$ estimaba que el problema era preocupante, el $90 \%$ consideraba de importancia disponer de una vacuna y un $87,9 \%$ estaba dispuesto a recibirla ${ }^{59}$.

Entre 1985 y 1988 más de 300 voluntarios del área de Pergamino fueron inoculados con la Candid, experiencia a cargo del grupo dirigido por el Dr. Maiztegui, en la que no se observaron efectos clínicos adversos 
y, en más del $90 \%$ se detectaron anticuerpos contra el virus Junín. El primero de estos voluntarios fue el mismo Maiztegui. Para llevar a cabo el estudio de efectividad e inocuidad a campo abierto, último paso para poder implementar una vacunación masiva, fueron seleccionadas 41 localidades del sur de la provincia de Santa Fe donde se había verificado una alta incidencia de la enfermedad ${ }^{60}$. El estado provincial dio su aval al estudio a través de la firma de un convenio con el Ministerio de Salud de la Nación, que fue refrendado por decreto del Gobernador ${ }^{61}$.

La convocatoria para los voluntarios se realizó a partir de una campaña de difusión que recurrió a reuniones y charlas informativas, recurso permanente impulsado por Maiztegui, como la distribución de folletos y afiches explicativos. Se hacía especial referencia a la no existencia de riesgo pues se había comprobado que la Candid era inocua e inmunogénica, participar del estudio, agregaban, era un privilegio porque "representaba un acto de solidaridad y cooperación comunitaria" siendo la primera vez que se realizaba un estudio de tal importancia y magnitud en el país. Además, los voluntarios, contarían con la permanente supervisión y asesoramiento de los profesionales del Instituto de Pergamino y del Ministerio de Salud y Medio Ambiente de la provincia de Santa $\mathrm{Fe}^{62}$. También, se preparó un mensaje televisivo difundido por Canal 5 de Rosario (Santa Fe), un mensaje radial propagado por las emisoras de la ciudad, como radios de las localidades elegidas. Esto generó una verdadera movilización de la población, ya activa a partir de la preocupación generada ante la posibilidad de sufrir una enfermedad asociada con la muerte $y$, concientizada por el accionar del Dr. Maiztegui y sus colaboradores desde los inicios de los setenta cuando la virosis apareció en el sur santafesino. Además, debemos tener presente que, entre el grupo de Pergamino y la población del área epidémica, particularmente el sur de Santa Fe muy cercano a la citada ciudad, existía una relación médico-paciente: quiénes les proponían vacunarse era aquéllos que habían atendido en alguna ocasión a familiares, amigos y vecinos; aquéllos que habían llegado al pueblo, inmerso en la conmoción ante la epidemia, para dar una charla sobre la problemática: "cada vez que íbamos a un lugar estaba el enfermo tal que venía a saludarnos, que nos contaba cómo se le había caído el pelo, que le dolía la cabeza, [...] nosotros no éramos [...] desconocidos para esta comunidad, éramos la gente que los atendión ${ }^{\prime 63}$.

En cada pueblo o ciudad organizaron una comisión encargada de la inscripción y el registro de los voluntarios; colaboraron docentes y estudiantes de escuelas primarias y secundarias, cooperativas agrarias, municipalidades, el Rotary Club y agencias del Instituto Nacional de Tecnología Agropecuaria (INTA). Entre junio y septiembre de 1988 fueron inscriptos 7.559 voluntarios $^{64}$ sobre un total de 20.600 personas que reunían las condiciones para participar en el estudio, aproxi- madamente un $37 \%$. Finalmente fueron seleccionadas $5927^{65}$ personas, de sexo masculino de 15 a 60 años que trabajaban o residían en la zona rural.

Entre octubre de 1988 y enero de 1989 se llevó a cabo el estudio realizado en forma prospectiva, a doble ciego, es decir, el $50 \%$ de los voluntarios recibió la vacuna y el $50 \%$ restante una sustancia control ${ }^{66}$. Los centros de inoculación, nueve en total, estuvieron a cargo de personal del Instituto de Pergamino y profesionales, enfermeras y vecinos dispuestos a colaborar, de las distintas poblaciones implicadas. Al primer examen de control, en marzo de 1989, concurrió el 95\% de los inoculados, dato que indicaba el desarrollo sin inconvenientes del estudio y "un gran espíritu de colaboración de los voluntarios participantes"

A fines de 1990 Maiztegui, enfermo de cáncer, junto a Barrera Oro pudo comprobar en Estados Unidos, al romper los sellos de control de los pacientes y voluntarios inoculados, el 95,5\% de efectividad de la Candid I. La vacuna cumplía los requisitos para las vacunas vivas atenuadas como el sarampión, paperas, y poliomielitis. Así, la Fiebre Hemorrágica, convertida en endemia, podría ser controlada. En medio de la algarabía de investigadores, voluntarios y periodistas, la Lic. María Rosa Feulliade, Directora interina del Instituto de Pergamino, reconoció a esos voluntarios del sur de Santa Fe tan importante logro al expresarles "Ustedes son los responsables de esto; ustedes se inocularon esta sustancia cuando pocos creían en ella. El mérito, repito, es de ustedes" ${ }^{\prime \prime 8}$. El personal de este centro de investigación se abocó inmediatamente a cumplir con el compromiso asumido al iniciar los estudios que era el de inocular a todo aquéllos voluntarios que habían recibido el placebo.

\section{CONCLUSIONES}

Las actitudes temerosas de la población epidémica ante la posibilidad de inocularse la vacuna de Pirosky encontrarían su explicación en el hecho que las campañas no estuvieron acompañadas o impulsadas por los médicos del área epidémica quiénes contaban con amplio reconocimiento por parte de la población como únicos especialistas en FHA. Los investigadores del Instituto Malbrán, a cargo de la vacunación, eran unos desconocidos para los habitantes del noroeste bonaerense. Sin embargo el número de 15.000 personas inoculadas, cuando no era obligatorio, es importante e indica los recursos con que contaba el equipo del Instituto Malbrán -la Comisión Nacional-; circunstancia que demuestra el interés del gobierno frondizista en este proyecto, coincidentemente con el compromiso demostrado por esta gestión en impulsar a la ciencia en general.

La disposición de la población epidémica a vacunarse con la XJ Clon 3 se sustentó en el temor ante la en- 
fermedad que derivaba en la adopción de conductas preventivas y, fundamentalmente, en la presencia de los médicos locales en la implementación de las campañas de vacunación. Las movilizaciones populares a favor de la vacuna fueron impulsadas por el incremento de número de casos y por los artículos publicados en periódicos, donde, aparecían nuevamente los médicos de Junín afirmando la validez de la XJ Clon 3. La manifiesta y verbalizada adhesión de la población contrasta con el número de sólo 636 vacunados circunstancia que obedecería a las limitaciones del equipo de Parodi en orden a los recursos y al hecho que una cátedra no es el ámbito adecuado, por razones técnicas, para desarrollar una vacuna. La presencia del estado provincial como nacional auspiciando la vacunación demuestra, nuevamente, el interés estatal en la cuestión de la FHA que, en términos de morbilidad, no tenía la importancia de otras enfermedades como es el caso, por ejemplo, del Mal de Chagas Este interés se sustentó en el impacto socioeconómico de la enfermedad y, el espacio que la misma encontró, en los medios de comunicación.
El vínculo médico-paciente desarrollado por Maiztegui y su grupo con la población epidémica, la concientización de la población a través de campañas de educación para la salud implementadas en el marco del Programa Nacional de Prevención y Lucha contra la FHA y, el persistente temor por la enfermedad, ante la reiteración de los brotes, justifican el importante número de 6000 voluntarios para realizar el último estudio de la vacuna Candid. La virosis, además, continuó encontrando espacio en los medios de comunicación, ya no sólo periódicos sino también canales de televisión, que resultaron instrumentos fundamentales en la implementación de las campañas de educación para la salud, particularmente aquéllas en las que convocaban a voluntarios para la vacunación.

La presencia del estado, tanto gobiernos de facto como democráticos, promoviendo los proyectos de desarrollo de vacunas demuestran el continuo interés del estado en la problemática del Mal de los Rastrojos, si bien esto no siempre se tradujo en la transferencia de recursos suficientes.

\section{NOTAS}

1 Fue denominada científicamente como Fiebre Hemorrágica Argentina por el Dr. Humberto Rugiero, aludiendo a sus síntomas característicos, como fiebre y una tendencia a las hemorragias, y a que se localiza únicamente en nuestro país.

2 El equipo estaba integrado por los doctores Ernesto Molinelli Wells, Juan Zuccarini, Arturo Di Pietro, Pedro Martini, Julio Barrera Oro, Alberto Pfeifer, Lidia Martos, Matilde D’Empaire y el técnico Luis Gutman Frugone.

3 Este "team" científico estaba conformado por los Dres. Marcelo Frigerio, Norma E. Metler, Félix Garzón, Marta Boxaca, Lucía de Guerrero, Nora R. Nota, Enrique Rivero y José María de la Barrera, todos miembros de la cátedra de Parasitología y Microbiología. Y por los Dres. Laura Astarloa, Carlos González Cambaceres, Francisco Maglio, Guido Squassi, Enrique Libonatti, Diana Fernández y la Dra. Giacosa, de la Cátedra de Enfermedades Infecciosas Este fue el primer grupo científico en iniciar trabajos de investigación vinculados con la Fiebre Hemorrágica Argentina.

4 Testimonio oral de los Dres Ernesto Molinelli Wells y Julio Barrera Oro (equipo de Pirsoky) y de las Dras. Nora Nota y Marta Boxaca (equipo de Parodi). La intensa competencia es una de las características de todo campo científico (Bourdie, 2003).

5 En Argentina el factor económico fue el motor de la primera acción de sanidad rural impulsada por el gobierno central, a principios del siglo XX, en zonas afectadas por el Paludismo (Álvarez, 2010, p. 38).

6 El rastrojo es el residuo (tallos y hojas) que queda en la tierra luego de segar. En el rastrojo del maíz se encontraban los nidos de las lauchas transmisoras de la enfermedad, los peones trabajaban y vivían sobre estos rastrojos.

7 La idea, como él mismo lo testimonió, había sido del propio director del Malbrán, Dr. Pirosky, basándose en trabajos de científicos soviéticos con agentes virales causantes de otras Fiebres Hemorrágicas de los años '30.

8 El equipo que la había desarrollado estaba integrado por los Dres. Juan Zuccarini, Ernesto Molinelli Wells, Pedro Martini, Arturo Di Pietro, Lidia Martos y Matilde D’Empaire. Una publicación científica, la única del equipo referida a la vacuna, testimonia los trabajos realizados; en las conclusiones afirmaban que "se ha obtenido una vacuna a base de virus específico muerto por formol con un porcentaje de protección en la rata blanca de un $50 \%$ sobre 100 dosis mortales", en "Virosis Hemorrágica del Noroeste Bonaerense: la vacuna específica y la vacunación", Orientación Médica (1959), 8 (363), Buenos Aires, p. 743.

9 La Razón, Buenos Aires, 21 de julio de 1959, p. 9. La Prensa, Buenos Aires, 21 de julio de 1959, p. 8. La Nación, Buenos Aires, 21 de julio de 1959, p. 7. Clarín, Buenos Aires, 21 de julio de 1959, S/no de p. El Mundo, Buenos Aires, 21 de julio de 1959, p.

10 Clarín, Buenos Aires, 21 de julio de 1959, p. 9; La Nación, Buenos Aires, 21 de julio de 1959 p. 7; La Prensa, Buenos Aires, 21 de julio de 1959, p. 8 y El Mundo, Buenos Aires, 21 de julio de 1959 , p. 6.

11 La Razón, Buenos Aires, 3 de agosto de 1959, p. 4.

12 Diario de Sesiones - Cámara de Diputados (1959) - Congreso Nacional, Buenos Aires, Imprenta del Congreso de la Nación, pp. 1977 a 2013.

13 La Razón, Buenos Aires, 17 de agosto de 1959, p. 8. 
14 La Comuna de Alberti, Alberti, 25 de Febrero de 1960, El Oeste, 27 de Febrero de 1959, El Censor, Bragado, 2 de marzo de 1960 y El Diario de Nueve de Julio, Nueve de Julio, 14 de marzo de 1960 .

15 Este método fue implementado, en forma empírica, a fines del brote de 1958 por los Dres. Cintora y Magnoni del Centro de Prevención y Tratamiento de FHA de Junín. Los investigadores de la Comisión Nacional criticaron el método por falta de rigorismo científico y se opusieron a su utilización. Las razones que esgrimían eran válidas debido a que científicamente no estaba demostrado su eficacia. Por otra parte, no había un control estricto del plasma utilizado y se trataba de enfermos de Fiebre Hemorrágica diagnosticada clínicamente pero no en el laboratorio. La falta de control planteaba la posibilidad que junto con el plasma se pudieran introducir otras enfermedades infecciosas o, como ocurrió, que no se tratara de plasma inmune por un diagnóstico erróneo en el dador, pero era a los médicos locales a quienes se les morían los pacientes, con el plasma observaron buenos resultados y lo siguieron empleando si bien no lo documentaron científicamente. La corroboración científica de la utilidad del Plasma de convaleciente fue realizada posteriormente por el Dr. Julio Maiztegui en el período 1974-1978.

16 En este centro bajo la dirección del Dr. Héctor A. Ruggiero se desempeñaron los doctores Alberto Cintora y Clemente Magnoni, a cargo del pabellón de emergencia, Fernando Pérez Izquierdo, integrante del cuerpo médico y Héctor Antonio Milani, jefe de Laboratorio.

17 Testimonio oral de Eder Ober Pagano y Rosa de Finamore, habitantes de O’Higgins durante el período 1958-1963.

18 Clarín, Buenos Aires, 27 de julio de 1959, p. 28.

19 Sociedad Rural Argentina: entidad que representa a los grandes propietarios de tierras.

20 La Razón, Chivilcoy, 4 de julio de 1962, p. 1.

21 Federación Agraria Argentina: entidad que nuclea a pequeños y medianos productores agrícolas.

22 La Verdad, Junín, 8 de julio de 1962, p. 2.

23 La Prensa, Buenos Aires, 21 de julio de 1962, p. 6.

24 El equipo estaba conformado por médicos, investigadores y técnicos del Instituto Malbrán, del Centro Piloto de Atención Médica de la Comunidad y del Centro de Educación Médica e Investigaciones Clínicas (CEMIC)

25 Dres. Rodolfo Carcavallo, Víctor D’Arienzo y Rodolfo Cogorno, respectivamente.

26 Dres. Clemente Magnoni, Fernando Pérez Izquierdo, Héctor Ruggiero, Héctor A Milani y Alberto Cintora.

27 La Verdad, Junín, 23 de marzo de 1969, p. 2

28 Solicitada firmada por Vecinos de Rancagua en La Opinión, Pergamino, 15 de junio de 1974, p. 3.

29 Testimonio del Dr. Santero, médico de Rancagua en Revista Gente, Buenos Aires, 6 de junio de 1974, p. 11.
30 La Razón, Buenos Aires, 18 de mayo de 1970, s/no de p.

31 Fiebre Hemorrágica Argentina (1987, folleto), Pergamino, Programa Nacional de Lucha contra la FHA, Secretaría de Salud, Ministerio de Salud y Acción Social de la Nación, pp 1-22, p. 11.

32 La Opinión, Pergamino, 28 de mayo de 1970, p. 9.

33 Los inoculados eran de los partidos de Junín, Pergamino, Rojas, General Arenales, Alem, Chacabuco, Ramallo, Bartolomé Mitre, Colón y las localidades de Rancagua y La Violeta (Partido de Pergamino), Ferré y Arribeños (Partido de General Arenales), Pérez Millán (Partido de Ramallo), Rafael Obligado (Partido de Rojas), Vedia (Partido de Alem), Morse, Agustina, Cuartel Quinto (Partido de Junín).

34 Estudios realizados tres meses después de la inoculación indicaron que un $93 \%$ de los vacunadas tenían anticuerpos contra el virus Junín en Ruggiero, Héctor, Magnoni, Clemente, BarceIona, Lucía, Milani, Héctor Antonio, Pérez Izquierdo, Fernando, Milani, H. L., Evolución alejada de vacunados contra la Fiebre Hemorrágica Argentina con la cepa atenuada XJ Clon 3, Estudio clínico, humoral e inmunológico 7 a 9 años después de su inoculación, S/otros datos, Archivo personal del Dr. Héctor Luis Milani.

35 Testimonio oral del Dr. Héctor Luis Milani, bioquímico del Centro de Investigación y Tratamiento de Junín.

36 La Comisión Nacional Coordinadora, organismo creado durante la presidencia de Illia para coordinar todos los trabajos científicos vinculados a la FHA, designó a un grupo integrado por los Dres. Julio Barrera Oro - Jefe División Arbovirus del Instituto Malbrán-, Ramón Alberto de Torres - Profesor Titular de Microbiología de la Facultad de Medicina de la UBA-, Marta Sabattini - Jefe del Programa de FHA del Instituto de Virología de Córdoba- y Alois Bachmann -Investigador, Profesor Titular de Microbiología de la Facultad de Medicina del Salvador-.

37 La historia de pasajes de la cepa y su forma de preparación no respondían a las normas de producción de vacunas para uso humano conforme lo establecido por la OMS. La cepa de la vacuna tenía un pasaje por cerebro de ratón lactante y se había obtenido por clonado en cultivo de tejidos de conejo, que podía hipotéticamente arrastrar virus oncogénicos. La OMS había sido creada en 1948 como agencia multilateral de salud y, a pesar del contexto de la Guerra Fría, había logrado legitimarse como institución fundamental para la promoción de la salud pública y como centro autorizado de información sanitaria.

38 Informe del grupo de Trabajo designado para evaluar las acciones desarrolladas en nuestro país en la búsqueda de un antígeno específico contra la Fiebre Hemorrágica Argentina, Buenos Aires, 27 de agosto de 1973. Dictamen solicitado por el Subsecretario de Salud Pública de la Nación Dr. Domingo Liotta, expedido el 16 de octubre de 1973 y aprobado por el Plenario Académico en la Sesión del 30 de octubre de 1973, Buenos Aires. Archivo del Instituto de Enfermedades Virales Humanas “Dr. Julio I Maiztegui" - Pergamino.

39 Testimonio oral de los Dres. Julio Barrera Oro y Marta Sabattini investigadora del Instituto de Virología "Dr. José María Vanella" de la Universidad Nacional de Córdoba (Argentina) quien organizó un equipo destinado a la investigación en FHA. 
40 Fiebre Hemorrágica Argentina (1987, folleto), Pergamino, Programa Nacional de Lucha contra la FHA, Secretaría de Salud, Ministerio de Salud y Acción Social de la Nación, pp 1-22, p. 11.

41 El Tiempo, Pergamino, 6 de mayo de 1974, s/no de p.

42 La Opinión, Pergamino, 22 de mayo de 1974, p.5. La Nación, Buenos Aires, 27 de mayo de 1974, p.4.

43 La Opinión, Pergamino, 24 de mayo de 1974, p. 5.

44 El Dr. Marino Aguirre quien se había desempeñado como Jefe de la sala de Fiebre Hemorrágica del Hospital municipal San José de Pergamino, y había renunciado, en 1971, al trasladarse esa sala al Hospital provincial Rodríguez Jáuregui.

45 La Opinión, Pergamino, 17 de mayo de 1974, p. 8.

46 Frente Justicialista de Liberación, denominación del Partido Peronista en el gobierno.

47 La Opinión, Pergamino, 17 de mayo de 1974, p. 5.

48 Revista Gente, Buenos Aires, 6 de junio de 1974, p. 11.

49 La Opinión, Pergamino, 13 de junio de 1974, p. 11.

50 Estuvieron presentes los Dres. Osvaldo Carena, interventor, Julio Barrera Oro, Jefe del Departamento de Virus,, Lucio Leverone, Secretario científico, Raúl Santino, Secretario de producción, del Instituto Malbrán; Giani Villani, Subsecretario de Medicina Sanitaria, Benítez Sosa, Director de Zoonosis, Rodríguez Naso, Coordinador de la IV Zona Sanitaria, Dr. Liotta, Secretario de Salud Pública, del Ministerio de Salud Pública de la Nación; Herminio Zatti, Subsecretario de Seguridad Social de la Provincia de Buenos Aires; Dres. Milani, Magnoni, Pérez Izquierdo del Centro de Prevención y Tratamiento de FHA de Junín; Dr. Maiztegui, Jefe de la Sala Virósica del Hospital Rodríguez Jáuregui.

51 La Opinión, Pergamino, 21 de julio de 1974, p. 11.

52 La Opinión, Pergamino, 30 de mayo de 1974, p. 8.

53 Ruggiero, Héctor, Magnoni, Clemente, Barcelona, Lucía, y otros, "Evolución alejada de vacunados contra la Fiebre Hemorrágica Argentina con la cepa atenuada XJ Clon 3, Estudio clínico, humoral e inmunológico 7 a 9 años después de su inoculación"', S/ otros datos. Archivo personal del Dr. Héctor Luis Milani.

54 Hasta el momento carecemos de datos que nos permitan analizar las circunstancias de esta designación.

55 La atención primaria de la salud es la asistencia sanitaria esencial basada en métodos y tecnologías prácticas, científicamente fundados y socialmente aceptables, puesta al alcance de todos los individuos de la comunidad, Declaración de Alma-Ata (1978).

56 La falta de interés comercial de los laboratorios privados también es mencionada en el caso de desarrollo de investigaciones clínicas sobre tratamiento de Chagas (Kreimer, 2010a, pp. 405428 , p. 410 , p. 415 )

57 A principios de la década del 70 se estimaba que unas 10.000 personas habían padecido la enfermedad en nada equiparable a los 4 millones de personas afectadas por el Mal de Chagas.

58 El Dr. Barrera Oro explicó que "Candid en inglés significa pura, [...] sin propósitos secundarios".

59 V Reunión Anual del Programa Nacional de Lucha contra la FHA (1985), Archivo del Instituto Nacional de Enfermedades Virales Humanas "Dr. Julio I. Maiztegui".

60 San José de la Esquina, Arequito, Los Molinos, Casilda, Pujato, Berabevú, Los Quirquinchos, Cañada de Ucle, Villada, Chabás, Sanford, Fuente, Chovet, Firmat, Bombal, Bigand, Villa Mugueta, Arminda, Acebal, Miguel Torres, Carreras, Alcorta, Máximo Paz, Pavón Arriba, Uranga, Labordeboy, Hughes, Rueda, Cepeda, Godoy, J.B. Molina, Sargento Cabral, Peyrano, Cañada Rica y General Nelly.

61 Decreto № 0463 del 30 de enero de 1989.

62 Anuncio del estudio para establecer la eficacia de la Candid I realizado en la VIII Reunión Anual del Programa Nacional de Lucha contra la FHA que tuvo lugar en Rosario en La Capital, Rosario, 25 de junio de 1988, p. 1 y 5.

63 Testimonio oral de la Dra. Delia Enría, actual Directora del Instituto Nacional de Enfermedades Virales Humanas (INEVH) "Dr. Julio I. Maiztegui", de la Lic., María Rosa Feulliade, estadístico, desde 1978, y actual Jefe del Departamento de Capacitación del citado instituto y de Ángel Raúl Masanessi integrante de la Asociación de Lucha contra la Fiebre Hemorrágica Argentina (ALFHA) de Pergamino, en 1965, y de la actual fundación "Julio Maiztegui".

64 "Inoculación de voluntarios humanos con la vacuna Candid 1 de Virus Junin (1989)", IX Reunión Anual del Programa Nacional de Lucha contra la Fiebre Hemorrágica Argentina, Pergamino, INEVH, pp 1-30, p 5.

65 Nota enviada al Director Nacional de Institutos e Investigación Dr. Luis Pedro Mujica del Ministerio de Salud y Acción Social de la Nación por el Dr. Julio Maiztegui como Director del Instituto de Pergamino - Archivo del INEVH.

66 La vacuna contra la Fiebre Hemorrágica Argentina - Información para profesionales (1994, folleto), Pergamino, INEVH, Ministerio de Salud y Acción Social de la Nación.

67 Nota enviada al Director Nacional de Institutos e Investigación Dr. Luis Pedro Mujica del Ministerio de Salud y Acción Social de la Nación por el Dr. Julio Maiztegui como Director del Instituto de Pergamino - Archivo del INEVH.

68 La Nación, Buenos Aires, 30 de noviembre de 1990, S/no p. 


\section{BIBLIOGRAFÍA}

Agnese, Graciela (2003), Primeros Investigadores de la FHA 19531963, Separata, Buenos Aires, Duodécimo Congreso Nacional y Regional de Historia Argentina. Academia Nacional de la Historia.

Agnese, Graciela (2005), "Desarrollo de la primer vacuna contra la Fiebre Hemorrágica Argentina 1959-1962". En: César Lorenzano (ed.), Historias de la Ciencia Argentina II, Buenos Aires, Universidad Nacional de Tres de Febrero y Grupo Argentino de Historia de la Ciencia, pp. 153-166.

Agnese, Graciela (2007), "La Intervención al Instituto Malbrán y la fuga de cerebros". En: Lorenzano, César (ed.), Historias de la Ciencia Argentina III, Buenos Aires, Universidad Nacional de Tres de Febrero y Grupo Argentino de Historia de la Ciencia, pp. 46-57.

Álvarez, Adriana (2010), Entre muerte y mosquitos. El regreso de las plagas en la Argentina (siglos XIX y XX), Buenos Aires, Biblos.

Armus, Diego (2007), La ciudad impura, Salud, tuberculosis y cultura en Buenos Aires, 1870-1950, Buenos Aires, edhasa.

Armus, Diego (ed.) (2005), Avatares de la medicalización en América Latina 1870-1970, Buenos Aires, Lugar editorial.

Armus, Diego (ed.) (2002), Entre médicos y curanderos, Buenos Aires, Grupo Editorial Norma.

Babini, José (2000), Historia de la Medicina, Barcelona, Gedisa.

Babini, José (1971), La Ciencia en la Argentina, Buenos Aires, Eudeba.

Barcelona, Lucía; Weissenbacher, Mercedes; Parodi, Armando (1969), "Inmunización contra la Fiebre Hemorrágica Argentina con una cepa atenuada del virus Junín. I. Estudio de una cepa modificada del virus Junín - Inmunización de cobayos", Medicina, 29 (1), pp.1-4.

Belmartino, Susana (2005), La Atención Médica Argentina en el Siglo XX, Buenos Aires, Siglo XXI.

Bourdieu, Pierre (2003), Los usos sociales de la Ciencia. Buenos Aires, Ediciones Nueva Visión.

Carter, Eric (2008), "Malaria, Landscape, and Society in Northwest Argentina in the Early Twentieth Century", Journal of Latin American Geography, 7 (1), s/no de pp.

Castoriadis, Cornelius (1993), La Institución Imaginaria de la Sociedad, Buenos Aires, Tusquets.

Cereijido, Marcelino (1990), La nuca de Houssay - La ciencia argentina entre el Billiken y el exilio, Buenos Aires, FCE.

Cueto, Marcos; Brown, Theodore; Free, Elizabeth (2011), "El proceso de creación de la Organización Mundial de la Salud y la Guerra Fría", Apuntes, XXXVIII (69), pp 129-156.

Cueto, Marcos (2004a), El Valor de la Salud - Historia de la OPS, Washington, OPS.

Cueto, Marcos (2000), El Regreso de las Epidemias, Salud y Sociedad en el Perú del siglo XX, Lima, IEP (Instituto de Estudios Peruanos).
Da Rocha, Cristina María (2003), "Comunicação social e vacinação", História, Ciências, Saúde-Manguinhos, 10 (2), pp. 795-806.

Díaz, Esther (ed.) (1996)), La Ciencia y el Imaginario Social, Buenos Aires, Biblos.

Di Liscia, María Silvia (2011), "Marcados en la piel: vacunación y viruela en Argentina (1870-1910)", Ciencia \& Saúde Coletiva, 16 (2), pp 409-422.

García Belsunce, Floria (1989), Historia Política de la Argentina Contemporánea 1880-1983, Buenos Aires, Alianza Universidad.

García Belsunce, Floria (1992), Historia de los argentinos, T. II, Buenos Aires, Larousse.

Frigerio, Marcelo (1977), "Prevención de la FHA", Ciencia e Investigación, 33, pp. 265-274, p. 269.

Kreimer, Pablo; Romero, Lucía; Bilder, Paula (2010a), “¿Tratar o no tratar? La controversia científica sobre el tratamiento para los enfermos de Chagas crónico", Asclepio, 62 (2), pp. 405-427.

Kreimer, Pablo; Thomas, Hernán (2004), Producción y uso social de conocimiento, Buenos Aires, Universidad Nacional de Quilmes.

Lobato, Mirta (ed.) (1996), Política, médicos y enfermedades, Buenos Aires, Biblos-Universidad Nacional de Mar del Plata.

Maiztegui, Julio (1977), "Epidemiología de la FHA", Ciencia e Investigación, 33, pp. 359-362, p. 361.

Maiztegui, Julio (1991), “Fiebre Hemorrágica Argentina”. En: Gorodner, Jorge Osvaldo y colaboradores (eds.), Patología Regional Argentina, Buenos Aires, Fundación Argentina, Capítulo X

Martínez Pintos, Ismael (1960), Mal de los Rastrojos - Fiebre Hemorrágica Epidémica del Noroeste de la Provincia de Buenos Aires, La Plata, Gobernación - Comisión de Investigación Científica, p. 27.

Martins, Reinaldo; Maia, María de Lourdes (2003), “Eventos adversos pós-vacinais e resposta social", História, Ciências, SaúdeManguinhos, 10 (2), pp. 807-25.

Metler, Norma (1970), Fiebre Hemorrágica Argentina: conocimientos actuales, Washington, Organización Panamericana de la Salud, Oficina Sanitaria Panamericana, Oficina Regional de la Organización Mundial de la Salud, publicación científica № 183.

Moulín, Anne Marie (2003), "A hipótese vacinal: por uma abordagem crítica e antropológica de um fenômeno histórico", História, Ciências, Saúde-Manguinhos, 10 (2), pp. 499-517.

Nuñez, Sergio; Orione, Julio (1995), Disparen contra la ciencia, De Sarmiento a Menem, nacimiento y destrucción del proyecto científico argentino, Buenos Aires, Espasa Calpe.

Pirosky, Ignacio (1986), 1957 - 1962 Progreso y Destrucción del Instituto Nacional de Microbiología, Buenos Aires, Eudeba.

Pirosky, Ignacio; Zuccarini, Juan; Molinelli, Ernesto A.; Barrera Oro, Julio G.; Martini, Pedro; Copello, Andrés R. (1959), Virosis He- 
morrágica del Noroeste Bonaerense, Buenos Aires, Ministerio de Asistencia Social y Salud Pública, Instituto Nacional de Microbiología.

Reig, Osvaldo (1992), Excelencia y Atraso, Buenos Aires, Ediciones de la Flor.

Ruggiero, Héctor; Magnoni, Clemente; Nota, Nora; Milani, Héctor A.; Pérez Izquierdo, Fernando; Maglio, Francisco; Astarloa, Laura; González Cambaceres, Carlos; Milani, Héctor L. (1982), Fiebre Hemorrágica Argentina, Buenos Aires, El Ateneo.

R. B. (1984), “César Milstein y la destrucción del Instituto Malbrán. En: Todo es Historia, Buenos Aires, 211, pp 77-81.

Sabattini, Marta; Maiztegui, Julio (1970), "Fiebre Hemorrágica Argentina”, Medicina, 30, (Suplemento 1), pp. 111-128, p. 116
Sánchez Ron, José Manuel (1997), “Ciencia, Tecnología y Cambio Social". En V Conferencias Internacionales de Historia - Para comprender el cambio social - Enfoque teórico y perspectivas historiográficas, Pamplona, Eunsa.

Sontag, Susan (2003), La enfermedad y sus metáforas, el sida y sus metáforas, Buenos Aires, Taurus.

Weissenbacher, Mercedes; Barcelona, Lucía; Help, Guillermina; Parodi, Armando (1969), "Inmunización contra la FHA con una cepa atenuada de virus Junín. III”, Medicina, 29 (2), pp. 88-92, p. 88.

Zabala, Juan Pablo (2010), La enfermedad de Chagas en la Argentina, Investigación científica, problemas sociales y políticas sanitarias, Bernal, Universidad Nacional de Quilmes. 